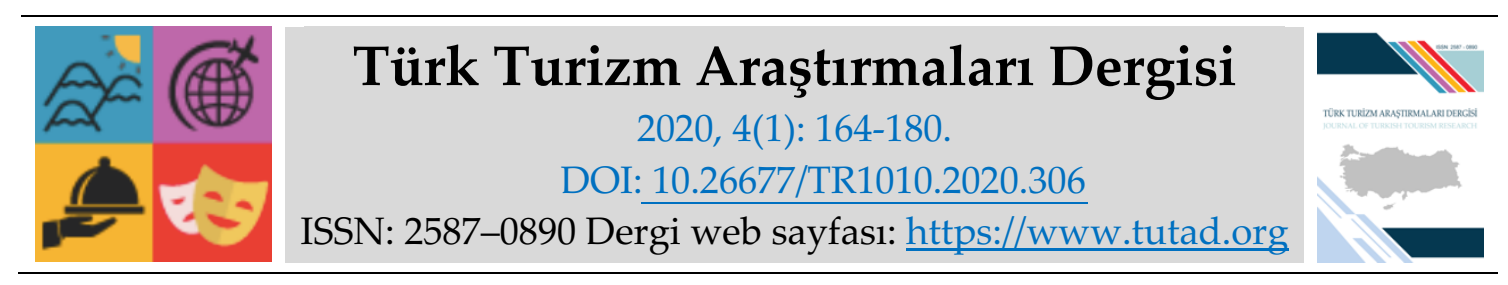

$\underline{\text { ARASTIRMA MAKALESI }}$

\title{
Etkinliklerin Sürdürülebilirliği ve Eko-Etkinlikler: A Greener Festival Örneği
}

Buse AYDIN, Çanakkale Onsekiz Mart Üniversitesi, Sosyal Bilimler Enstitüsü, Turist Rehberliği Yüksek Lisans Öğrencisi, Çanakkale, e-posta: buseaydin1421@gmail.com ORCID: https://orcid.org/0000-0002-0474-5638

Doç. Dr. Hacı Mehmet YILDIRIM, Çanakkale Onsekiz Mart Üniversitesi, Turizm Fakültesi, Çanakkale, e-posta: hadjimehmet@gmail.com ORCID: https://orcid.org/0000-0003-0718-7296

\section{Öz}

Turizm sektöründe etkinlikler, kültürel değerlerin tanıtılması, ekonominin gelişmesi ve destinasyonlara turist çekmesi açısından önemli bir yere sahiptir. Ancak etkinliklerin çevreye olan etkilerine bakıldı̆̆ında, binlerce ton atık oluşturma, çevre kirliliği yaratarak doğal ve kültürel varlıkların tahrip edilmesi gibi olumsuz etkilere sebep olabilmektedir. Etkinliklerin çevreye olan olumsuz etkisini azaltmak için son yıllarda yeni bir etkinlik türü olan "eko-etkinlikler" ortaya çıkmıştır. Bu araştırmada sürdürülebilir turizme değinilerek, eko-etkinliklerin ne olduğu ve neden gerekli olduğu hakkında kavramsal bir çalışma yapılmıştır. Ayrıca eko-etkinlikleri değerlendiren uluslararası kurum ve kuruluşlardan biri olan A Greener Festival kuruluşu ile ilgili bilgi verilmiştir. Araştırmanın amacı, A Greener Festival Ödülleri'nde ödül almış etkinliklerin sınıflandırılmasıyla, etkinliklerin ya da festivallerin sürdürülebilir olabilmesi için gerekli eko uygulamaları belirlemektir. "A Greener Festival" adlı sivil toplum kuruluşunun 2017 yılında 4 dalda (seçkinler, yüksek düzeyde tavsiye edilenler, önerilenler, gelişmekte olanlar) verdiği ödüllerin eko uygulamaları incelenmiş ve seçkinler ve yüksek düzeyde tavsiye edilenler kategorilerindeki etkinlikler nitel araştırma yöntemlerinden içerik analizi ile analiz edilmiştir. Çalışmanın sonucunda 4 dalda ödül alan festivallerin sürdürülebilir faaliyetleri (atık yönetimi, kullanılan malzemeler gibi) festivallerinde uyguladıkları ve sürdürülebilir bir çevreye sahip olmanın bilincinde oldukları ortaya konmuştur.

Anahtar Kelimeler: Sürdürülebilir Turizm, Sürdürülebilir Festivaller, Eko-Etkinlikler, A Greener Festival. Makale Gönderme Tarihi: 21.05.2019

Makale Kabul Tarihi: 02.01.2020

\footnotetext{
Önerilen Atıf:

Aydın, B. ve Yıldırım, H. M. (2020). Etkinliklerin Sürdürülebilirliği ve Eko-Etkinlikler: A Greener Festival Örneği, Türk Turizm Araştırmaları Dergisi, 4(1): 164-180.

(C) 2020 Türk Turizm Araştırmaları Dergisi.
} 


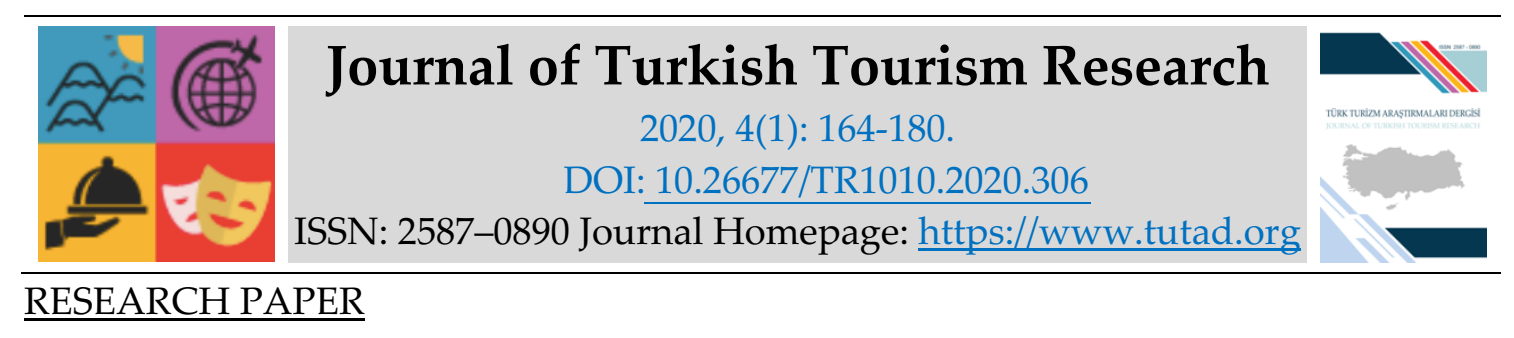

\title{
Sustainability of Events and Eco-Events: The Case of "A Greener Festival"
}

Buse AYDIN, Çanakkale Onsekiz Mart University, Institute of Social Sciences, Tourist Guidance Master Student, Çanakkale, e-mail: buseaydin1421@gmail.com

ORCID: https://orcid.org/0000-0003-0718-7296

Associate Prof. Dr. Hacı Mehmet YILDIRIM, Çanakkale Onsekiz Mart University, Faculty of Tourism, Çanakkale, e-mail: hadjimehmet@gmail.com

ORCID: https://orcid.org/0000-0003-0718-7296

\begin{abstract}
Events are very important in tourism sector in terms of the introduction of cultural values, development of economy and attracting tourist to destinations. However, considering the environmental impacts of events, they can cause negative impacts like creating thousands of ton waste and destruction of cultural and natural assets by creating environmental pollution. In order to reduce the negative impact of events on the environment, one of the new type of events, 'ecoevents' has emerged in recent years. In this research, a conceptual study has been made about sustainable tourism and what eco-events are and why it is necessary. Also, information was given about the A Greener Festival institution which is one of the international institutions evaluating eco-events. The aim of the study is to determine the necessary eco related activities for the sustainability of the events or festivals by classifying the events awarded at the A Greener Festival Awards. The eco related activities of the 4 awards (outstanding, highly commended, commended, improvers) given by A Greener Festival non- governmental organization in 2017 were analyzed and the events in the outstanding and highly commended categories were analyzed by content analysis from qualitative research methods.
\end{abstract}

Keywords: Sustainable Tourism, Sustainable Festivals, Eco-Events, A Greener Festival. Received: 21.05 .2019

Accepted: 02.01.2020

\section{Suggested Citation:}

Aydın, B. and Yıldırım, H. M. (2020). Sustainability of Events and Eco-Events: The Case of "A Greener Festival", Journal of Turkish Tourism Research, 4(1): 164-180.

(C) 2020 Türk Turizm Araştırmaları Dergisi. 


\section{Gíriş}

Günümüzde hangi sektörden olursa olsun işletmeler, çevresel sorunlara duyarlı olmak durumunda olduklarını göz ardı etmemektedir. Turizm sektöründe de çevre çok önemli bir unsur olduğu için konaklama, seyahat, yiyecek-içecek ve rekreasyon işletmeleri çevreye duyarsız kalamamaktadırlar (Atay ve Dilek, 2013; Tutar, 2015). Turizm sektörünün bileşenlerinden biri olan etkinlikler birçok destinasyon için ekonomik, sosyal, kültürel ve eğitim açısından önemli faydalar sağlarken aynı zamanda turizmin gelişmesine de katkı sağlamaktadır (Dickson ve Arcodia, 2010). Metropollerde yaşayan bireyler, kalabalık kent yaşamından kaçmak istemekte ve bu doğrultuda turizm ve rekreasyon faaliyetlerine katılım göstermektedirler. Düzenlenen etkinlikler, turisti destinasyona çekerek bölgede turizm hareketliliğinin artmasına neden olmaktadır (Can, 2015). Etkinlikler, birçok uluslararası destinasyon için değerli ekonomik, sosyal, kültürel ve eğitimsel faydalar sağladığından ve turizmde potansiyel büyümeye yol açtığından dolayı turizm endüstrisinin önemli bir bileşenidir (Dickson ve Arcodia, 2010).

Getz (1997:16) etkinlik kavramını "Destinasyonların gelişmesini hızlandıran, imaj yaratılmasına ve destinasyonların sahip oldukları turistik çekiciliklerin tanınırlı̆̆ının arttırılmasına katkı sağlayan planlı, organize turistik olaylar ve faaliyetler" ve "etkinliklere katılmak amaciyla doğrudan seyahat edenler ve seyahatleri esnasında etkinliklere katılma eğilimi gösteren turistlerin oluşturduğu pazar bölümü" olarak iki şekilde tanımlamıştır. Başka bir tanıma göre etkinlikler, çeşitli amaçlar için organize edilen, belli bir kitleye herhangi bir mesajın verilmesi için planlanan, belirli bir yerde ve zamanda gerçekleştirilen planlı faaliyetlerin bütünüdür (Uygur ve Çelik, 2010; Ertan, 2013; Baysal vd., 2016).

Etkinlikler, önemli bir turistik çekicilik unsuru olduğundan dolayı, bir destinasyonu turistlerin ziyaret etmesine olanak vermek ve güzel zaman geçirmelerini sağlamak amacıyla düzenlenirler (Çelik, 2009). Etkinlikler veya festivallerin, turizme ve içinde bulunduğu toplulukların sosyal ve ekonomik sürdürülebilirliğine önemli katkıları bulunmaktadır (Dodds ve Walsh, 2018). Ayrıca etkinlikler, kültürel değerlerin tanıtımı, kentin tutundurulması, şehre turist çekilmesi ve yerel halk için eğlence olanakları oluşturarak destinasyondaki yaşam kalitesini yükseltmeyi amaçlamaktadır (Yolal, 2017). Etkinliklerin olumlu yönlerinden ziyade, son dönemlerde olumsuz etkilerinden daha fazla söz edilmektedir. Düzenlenen etkinlikler, bölgede sosyal huzurun kaybolmasına, kalabalıklaşmaya, trafik sorunlarının ortaya çıkmasına, suç oranının artmasına, toplumda kimlik kaybına neden olabilir. Ayrıca etkinlikler, doğal ve fiziki çevreye verdiği zararlar konusunda da ön plana çıkmaktadır. Bu zararlar, doğal, tarihi ve kültürel kaynakların tahrip edilmesine ve bozulmasına yol açmaktadır (Koçak ve Balcı, 2010). Bunun sonucunda etkinlik sektörünün daha çevre dostu hale getirilmesi için bir takım yeni uygulamalara gidilerek, sürdürülebilirlik ilkesinin benimsenmesini gerektirmektedir. Çalışmada adı geçen etkinlik ve festivaller sürdürülebilirlik konusunda çok başarılı olup, diğer etkinlik ve festival organizatörlerine de bir fikir ve örnek teşkil etmektedir. Bu çalışmanın amacl, A Greener Festival Ödülleri'nde ödül almış etkinliklerin sınıflandırılmasıyla, etkinliklerin ya da festivallerin sürdürülebilir olabilmesi için gerekli eko uygulamaları belirlemektir.

\section{KAVRAMSAL ÇERÇEVE}

\section{Sürdürülebilir Turizm}

Sürdürülebilirlik kavramı ilk kez "1987 yılında Birleşmiş Milletler sponsorluğundaki Dünya Çevre ve Kalkınma Komisyonu'nun (WCED) yayınladığ ${ }_{1}$ "Ortak Geleceğimiz" adlı raporda ifade edilmiştir (Hauff, 1987:23). Bu rapor genel olarak, dünyayı tehdit eden çevresel sorunlar ve bu sorunlara yönelik çözüm önerilerinden oluşmaktadır (Koçak ve Balcı, 2010). Raporda geçen ve 
genel olarak kabul görmüş olan sürdürülebilirlik tanımı "Günümüzün gereksinimlerini, gelecek nesillerin kendi gereksinimlerini karşılayabilme yeteneklerinden ödün vermeden karşılayan kalkınma" olarak belirtilmiştir (Hauff, 1987). Başka bir deyişle sürdürülebilirlik; Bugünün ihtiyaçların karşılarken doğal kaynakları korumak ve gelecek nesillere iyi bir çevre bırakmak için yapılan faaliyetler olarak tanımlanabilir (Kuter ve Ünal, 2009). Sürdürülebilirlik, doğal çevrenin ve kaynaklarının korunmasının yanı sıra, gelecek nesillerin refahı ile ilgili olan her şeyi kapsamaktadır (Zifkos, 2015). Sürdürülebilirliğin gelişimi analiz edildiği zaman, birkaç önemli nokta bulunmaktadır: Birincisi, sürdürülebilirlik mevcut duruma bakmadan çevrenin korunmasında uzun zamandır devam eden bir yoldur. İkincisi, sürdürülebilirlik, nesiller arası ve nesiller arası eşitlenmiş refah seviyesini amaçlar. Üçüncüsü, gelişim düzeyi, sosyo-kültürel ve politik koşulları ne olursa olsun, tüm ülkelerde evrensel olarak etkili olabilir ve uygulanabilmektedir (Tosun, 2001).

Sürdürülebilirlik, son dönemlerde dünyada oldukça tartışılan bir konu haline gelmekte olup, iş dünyasında ve çeşitli sektörlerde de uygulanmaya başlanmıştır. Turizm sektörü doğal kaynakların hızlıca tükenmekte olması ve nüfus artışının hız kazanmasından dolayı ve "önce doğa" düşüncesinin benimsenmesi açısından önem arz eden bir sektördür (Kaypak, 2010; Vatan ve Poyraz, 2016). Ülkeler turizmden elde ettikleri gelir ile büyüme stratejilerini geliştirebilir; fakat bu büyüme stratejisi uygulanırken sürdürülebilirlik ilkeleriyle uyumlu çağdaş bir turizm gelişimi planlaması yaklaşımı içerinde olunmalıdır (Tosun, 2009). Taşıma kapasitesini ön planda tutan sürdürülebilir turizm yaklaşımı son zamanlarda bütün destinasyonlar ve ülkeler tarafından kabul gören bir anlayıştır (Mercan ve Özkök, 2013). Sürdürülebilir turizm, Dünya Turizm Örgütü (UNWTO) tarafından "Günümüz ve gelecekteki ekonomik, sosyal ve çevresel etkilerini tam olarak dikkate alarak; turistlerin, sektörün, çevrenin ve ev sahibi toplulukların ihtiyaçlarını karşılamayı benimseyen turizm" olarak tanımlanmıştır. Birleşmiş Milletler Çevre Programı (UNEP) ve Birleşmiş Milletler Dünya Turizm Örgütü (UNWTO) politikacılara hazırladıkları yönergede sürdürülebilir turizmin temel amaçları; ekonomik canlllk, yerel refah, istihdam kalitesi (ekonomik boyutu) sosyal eşitlik, ziyaretçi memnuniyeti, yerel kontrol, toplum refah, kültürel zenginlik (sosyal boyutu), fiziksel bütünlük, biyolojik çeşitlilik, kaynak verimliliği ve çevresel temizlik (çevresel boyutu) olarak ifade edilmiştir (Avcıkurt, 2015:203).

Sürdürülebilir turizm; ekonomik gelişme, çevrenin korunması ve yerel halkın sosyal fayda kazanması bakımından bir denge olarak kabul görmektedir. Bu doğrultuda; sürdürülebilir turizm stratejileri ve planları ile birlikte günümüzde elde edilen faydanın gelecekte de devam etmesi amaçlanmaktadır (Alkan, 2015). Özellikle gelişmekte olan ülkeler, turizm sektöründe sürdürülebilir kalkınmanın sağlanması için bazı ilkeler benimseyerek kaynaklarını korumakta ve bu ilkeleri ulusal politikalara ve planlara eklemektedirler. Turizmde sürdürülebilirliğin sağlanmasında sektörün benimsemesi gereken temel ilkeler genellikle şu şekildedir: (Duran 2011:304): (a) Yerel toplumun refahını arttırmak, (b) Kaynakların sürdürülebilir kullanımı, (c) Toplumlarda sosyal ve kültürel birleşmeyi sağlamak, (d)Yerel ekonomilerin desteklenmesi (e) Çalışanların eğitimine önem verilmesi, (f) Sorumlu turizm anlayışının benimsenmesi, (g) Aşırı tüketim ve atıkların önüne geçilmesi (h) Paydaşların fikirlerine danışılması.

Sürdürülebilir kalkınma için gelecekte gereksinim duyulacak insani ve doğal kaynakları korumak, sürdürmek ve geliştirmek, işletmelerin ve paydaşlarının ihtiyaçlarını karşılayan iş stratejileri ve faaliyetlerini yürütmek önem arz etmektedir (Presbury ve Edwards, 2005). Bu nedenle diğer turizm uygulamalarında olduğu gibi etkinlik ya da festival turizminde de sürdürülebilirlik ilkelerine uygun hareket edilmesi gerekmektedir. Sürdürülebilir etkinlikler, insanların değer verdiği önemli sosyal, kültürel ve çevresel rolleri yerine getiren etkinliklerdir. Getz (2009) Cape Town'daki Sorumlu Turizm Destinasyonları Bildirisi'ni, etkinlik sektörüne uyarlayarak sürdürülebilir bir etkinliğin nasıl olması gerektiğini aşağıdaki gibi belirtmiştir: (a) 
Etkinlikler olumsuz ekonomik, sosyal, kültürel ve çevresel etkileri en aza indirmelidir, (b) Yerel halk için daha büyük ekonomik faydalar sağlamak ve toplulukların refahını artırmayı amaçlamalıdır, (c) Çalışma koşullarını iyileştirmeli ve istihdam yaratmalıdır, (d) Yerel halkı karar verme sürecine dahil etmelidir, (e) Çeşitliliği sahiplenmeli, doğal ve kültürel mirasın korunmasına katkıda bulunmalıdır, (f) Ziyaretçilerin yerel halk ile anlamlı bir şekilde bağlantı kurmasını sağlayarak keyifli deneyimler yaratmalıdır, (g) Fiziksel olarak zorlanan insanlara erişim sağlamalıdır, (h) Kültürel duyarlılığa sahip olmalı, etkinlik katılımcıları ve ev sahipleri arasında saygıyı teşvik etmeli ve son olarak yerel gurur ve güven oluşturmalıdır.

Sürdürülebilirlik ilkeleri turizmi ilgilendiren her iş dalında benimsenmeli ve uygulanmalıdır. Turizm sektörünün önemli bileşenlerinden biri olan etkinlik ve festivaller de sürdürülebilirlik çerçevesinde çevreye olan zararı minimum seviyeye indirmeyi amaçlayarak organize edilmeli ve gerçekleştirilmelidir.

\section{Eko-Etkinlikler}

Dünya genelinde temiz su kaynaklarının \%17'si, orman ürünlerinin \% 25'i, enerji kaynaklarının $\% 40$ 'ı üstyapı yatırımları nedeniyle tükenmektedir. Yapılan araştırmalarda, turizm hizmeti veren işletmeler de \%20'lik bir pay ile bu tüketime ortak olmaktadır. Yaşamı giderek tehdit eden küresel iklim değişikliklerinde turizmin $\% 4,6$ payı bulunmaktadır. Turizm işletmelerinin büyüklügü ve konumu karbon salınımı ve küresel ssınma üzerinde etkili olabilmektedir. Bununla birlikte, turizm sektöründe konaklama işletmeleri, seyahat işletmeleri, müzeler, tema parklar, festival ve etkinlikler de farklı miktarlarda sera gazı salınımına sebebiyet vermektedir (Aksu ve İpar, 2018). Son zamanlarda birçok turizm işletmesi çevre dostu uygulamaları turizm yönetim planları kapsamında göz önünde bulundurarak bazı standartlar oluşturmaktadır. Bu standartların en önemlilerinden olan yeşil sertifikalar birtakım kriterlere bakılarak verilmektedir. Gelişmekte olan ülkelerde yeşil turizm sertifikasyonu kullanımı, kaynak yönetimine, çevrenin korunmasına ve kirlilik kontrolüne ilişkin uygulamalar sonucunda çevre dostu turizm anlayışını benimsemektedir (Erdoğan ve Tosun, 2009).

Eko etiketleme çevreye olan duyarlılığın göstergelerinden birisidir. Eko etiketleme, bir ürün, servis veya hizmetin hammadde temininden başlayıp, kullanım üretim ve kullanım süreçlerinin sonuna kadarki çevresel etkilerinin belirli sınırların altında olduğunu gösteren, Avrupa ve küresel kapsamda kabul gören ve güvenilen bir uygulamadır (Thøgersen vd., 2010). Eko etiketlemenin temel amacı tüketicileri çevre ve sağlık sorunlarına duyarlı hale getirmektir. Eko etiketleme ile tüketicilerin çevreye zarar vermeyen ürünleri tercih etmesi sağlanırken, üreticilerin de çevreye duyarlı üretim gerçekleştirmesi amaçlanmaktadır. Turizm işletmeleri için Yeşil Anahtar Programı Sertifikası, Mavi Bayrak Sertifikası, Avrupa Birliği Eko Etiketi, Yeşil Yıldız Sertifikası ve Yeşil Küre Sertifikası gibi birçok yeşil sertifikalandırma sistemleri bulunmaktadır. Bu sertifikalar, genel olarak sürdürülebilirlik anlayışını benimseyerek, turizm işletmelerinin çevre üzerindeki olumsuz etkilerini en aza indirgemek ve işletmelerin rakiplerinden farklılaşarak turist grupları üzerinde olumlu bir imaja bürünmesini sağlamayı amaçlamaktadır (Aslan ve Güneş, 2017; Aksu ve İpar, 2018).

Ekonomik olarak, etkinlikler, yerel ekonomiye katkıda bulunacak binlerce insanı beraberinde getirmekle birlikte, sosyal ve çevresel olarak, etkinlikler ve festivaller binlerce ton atık oluşturarak aşırı miktarda elektrik kullanımına, aşırı kullanım nedeniyle arazilere zarar vermeye ve $\mathrm{CO}_{2}$ emisyonlarını arttırmaya yol açmaktadır. Bu bağlamda etkinliklerin daha çevre dostu olabilmesi için giderek daha yenilikçi adımlar atılması gerekmektedir (Mair, 2014). Çevresel farkındalık düzeyinin artması beraberinde Birleşmiş Milletler'in birtakım çalışmalar yapmasına 
ve sürdürülebilirlik kavramı ile birlikte uluslararası düzeyde tedbirler alınmasına sebep olmuştur. Bu bağlamda Birleşmiş Milletler'in 1998 yılında iklim değişikliği ile mücadele kapsamında kabul ettiği Kyoto Protokolünde de karbon salınımını azaltmak adına yeni teknolojilerin geliştirilmesi, etkin kullanım ve sürdürülebilirlik gibi konular ön plana çıkmıştır (www.rec.org.tr). Alınan kararlar ve oluşan farkındalık beraberinde sürdürülebilirlik bakış açısının önemini ortaya çıkartmıştır. Bu bakış açısı paralelinde eko etkinlik kavramını oluşturmuştur (Uçak ve Villi, 2013). İşletmeler, faaliyetlerinin etkisi konusunda giderek daha fazla endişe duymakta ve kurumsal bir sürdürülebilirlik kültürünü benimseyerek değişimi etkileyebilmektedir. Yeşil bir etkinlik ya da festivalin planlanması ve yürütülmesi, sürdürülebilir uygulamalara başlamanın bir yolu olarak kolayca benimsenebilecek bir alandır (Graci ve Dodds, 2008).

Yeşil etkinlik olarak da adlandırılan eko-etkinlik, atıkları azaltma, enerji tasarrufu yapma, doğal kaynakların kullanımını en aza indirgeme ve doğaya minimum zararı verme amacıyla düzenlenen etkinlik ve/veya festivallerdir (Graci ve Dodds, 2008). Temel amaç, elektrikte harcanan enerji miktarı, geri dönüştürülen kağıt ve plastik miktarı, üretilen atık miktarı dikkate alındığında, atık ve enerji harcamalarını en aza indirgemektir (Zitz, 2011). Eko-etkinlikler, birtakım tedbirlerin alınmasıyla, olumsuz etkilerin ortadan kaldırılması açısından, sürdürülebilirlik kapsamında çevreye fayda sağlamayı amaçlamaktadır. Bu faydalar şu şekildedir (Graci ve Dodds, 2008; Dickson ve Arcodia 2010; www.cticc.co.za): (a) Eko-etkinlikler maliyet tasarrufu sağlar, (b) Kaynakların gereksiz kullanılmasını ve israf edilmesini önler, (c) Yenilenebilir enerji kaynaklarının kullanılmasını teşvik ederek çevre kirliliğini önler, (d) Yerel ürünlerin ve organik gıdaların kullanımını teşvik eder, (e) Müşterilere motivasyon sağlar ve müşteriler etkinliği düzenleyen organizasyon firmasına karşı olumlu bir imaj edinir, (f) Toplu taşıma araçlarının kullanımını teşvik ederek karbon emisyonunu azaltmaya çalışır.

Ahmad vd., (2013)'e göre, bir etkinliğe ev sahipliği yapmak, büyük miktarlarda su ve enerji israfı, atık ve sera gazı emisyonlarına sebep olduğundan dolayı etkinlik organizatörleri çevre üzerindeki etkilerini en aza indirgemek istemektedirler. İleriye dönük bir planlama, başarılı bir etkinliğe ulaşmanın en önemli unsurudur. Etkili bir planlama, sürdürülebilir kalkınma prensiplerini ve uygulamalarını tüm organizasyon seviyelerinde içermeyi kapsar ve bir etkinliğin ev sahipliği yapmasında sorumluluğu tümüyle ele almayı gerektirmektedir. Etkinlik planlayıcıları, sürdürülebilir bir etkinlik gelişimi için enerji verimliliği, atık ayrıştırma, su tüketimini en aza indirgeme ve ekolojik ürünleri tedarik etme gibi uygulamaları gerçekleştirmelidir (Ahmad vd., 2013). Laing ve Frost (2010) yaptıkları çalışmada festivallerin daha yeşil olabilmesi için, festivallerin enerji kaynaklarına ilişkin düzenlemeler, mekana ve kullanılan malzemelere ilişkin düzenlemeler, atık yönetimi, ulaşım ve sosyal düzenlemeler gibi konularda etkinlik organizatörlerine öneriler sunmuşlardır. A Greener Festival kuruluşunun ödüllendirdiği eko uygulamaları içeren festivaller de bu başlıklar altında değerlendirilmektedir.

\section{YÖNTEM}

Etkinliklerin sürdürülebilir ve daha yeşil olabilmesi için bir takım kuruluşlar bulunmaktadır. Bunlardan biri olan "A Greener Festival" dünyanın dört bir yanındaki etkinliklerin, festivallerin ve mekanların daha sürdürülebilir hale gelmesine ve çevresel etkilerinin azaltılmasına yardımcı olmayı amaçlayan kar amacı gütmeyen bir kuruluştur. Bu kuruluş, 2005'ten bu yana sürdürülebilirlik alanında öncü bir kuruluş olarak sertifika ödülleri, eğitim, uzmanlık gibi faydalar sağlamayı amaçlamaktadır (www.agreenerfestival.com). 
A Greener Festival, 2017'de Glastonbury Festivali (İngiltere), Roskilde Festivali (Danimarka), Bayou Boogaloo (ABD), Primavera Sound (İspanya) ve We Love Green'i (Fransa) içeren 5 kıtada 400'ün üzerinde festivali değerlendirmiştir. Çevre ve etkinlik yönetimi ile ilgili gerekli donanıma sahip olan AGF (A Greener Festival) denetleyicileri, 2015'te verilen ödüllerden bu yana sürekli eğitilmektedir. $\mathrm{Bu}$ zengin deneyim, çevresel etkilerin azaltılmasına yardımcı olmak ve sürdürülebilirliğin potansiyelini arttırmak için daha geniş etkinlik endüstrisine ulaşılmaktadır. $\mathrm{Bu}$ kuruluş, yerinde değerlendirme ve bağımsız doğrulama içeren ilk ve tek sürdürülebilir etkinlik sertifikası sağlamaktadır (www.agreenerfestival.com). Bu bağlamda çalışmanın amacı, sınıflandırma yapılarak etkinliklerin ya da festivallerin sürdürülebilir olabilmesi için gerekli ekolojik uygulamaları belirlemektir.

$\mathrm{Bu}$ araştırmada, 2005 yılından bu yana faaliyet gösteren A Greener Festival Kuruluşunun sitesinde 2017 yılında ödüllendirilen etkinliklerden "seçkinler" ve "yüksek düzeyde tavsiye edilen" etkinliklerin çevreci uygulamalarına yönelik içerik analizi yapılmıştır. Bu iki kategorideki festivallerin seçilme sebebi bu festivallerin daha fazla sürdürülebilir faaliyetler içermekte olduğudur. İçerik analizi, nitel araştırma yöntemlerine ilişkin veri analizinin temelini oluşturan, mesaj özelliği taşıyan her verinin bir amaç için taranması, kategorilere (temalara) bölünmesi, özetlenmesi ve bulguların araştırmanın amacı doğrultusunda analiz edilerek yorumlanmasını içeren bilimsel araştırma yöntemidir (Kozak, 2015; Karagöz, 2017). İçerik analizinde kelime, cümle, tema, paragraf, kavram, kategori vb. $t$ temel birimler kullanılmaktadır. Tema; bir metinde veya sanat eserinde anlatılmak istenen ana duygu, düşünce veya anlamdır. Kategori ise araştırmada elde edilen kavramların birbirleriyle belirli bir tema altında bir araya getirilmesidir (Karagöz, 2017). Bu araştırmada da A Greener Festival kuruluşunun 2017 yılında dört dalda vermiş olduğu ödüller kategorize edilerek analize tabi tutulmuştur.

\section{BULGULAR}

Dünya üzerinde uyguladı̆̆ı yeşil politikalar ile öne çıkan ve "yeşil festival" olarak değerlendirilen birçok festival bulunmaktadır. A Greener Festival kuruluşunun 2017 yılında 4 dalda (seçkinler, yüksek düzeyde önerilenler, önerilenler, gelişmekte olanlar) ödül verdiği festivallerin tamamı Tablo 1'de gösterilmektedir. Tablo 1'e göre seçkinler kategorisinde 4 festival bulunmaktadır. Bu festivaller aşağıdaki gibidir:

Green Gathering (İngiltere): The Green Gathering, eğitimin uygulamalı ve eğlenceli olması gerektiğine vurgu yapan sürdürülebilirlik eğitimidir. Festivale katılan tüm gönüllüler ve yönetmenler festivalin yapımında insanlara, hayvanlara ve çevreye saygılı olmayı taahhüt ederler. Festival esnasında atık, imha, kirlilik, fosil yakıt kullanımının en aza indirilmesi hedeflenmektedir. Festival, üretim şirketi ve yardım kuruluşu The Green Gathering tarafından üstlenilen tüm faaliyetler, çevresel sürdürülebilirliği, ekolojik farkındalığı, biyoçeşitliliği, insan haklarını ve uygun eğitimi, teknolojiyi ve iletişimi teşvik etmeyi amaçlamaktadır. 2017'de Greener Festival Ödülleri'nde üstün başarı ödülünü almaya hak kazanmıştır (www.greengathering.org.uk).

ØYA Festival (Norveç): Festival 2002 yılından bu yana, Norveç' in en büyük gençlik organizasyonu olan Natur og Ungdom (Norveç topraklarında genç arkadaşlar) ile festivaldeki çevresel etkinliklerle işbirliği yapmaktadır. Her yıl Natur og Undom'dan 200 gönüllü mükemmel bir iş çıkarmaktadırlar. Gönüllüler tüm festival alanını temiz tutarak geri dönüşüm ve atık yönetimi üzerinde çalışmaktadırlar. 2016 yılında düzenlenen festivalde toplanan tüm atıkların \%74'ü geri dönüştürülmüştür (www.greener-events.com). 
Tablo 1. A Greener Festival Ödüllerinde Ödül Alan Festivaller (2017)

\begin{tabular}{|l|l|}
\hline Seçkinler & Yüksek düzeyde önerilenler \\
\hline & Cambridge Folk Festival (UK) \\
Green Gathering (UK) & BAM18 (NL) \\
ØYA Festival (NO) & DGTL Festival (NL) \\
We Love Green (FR) & Extrema Outdoor (NL) \\
Wood Festival (UK) & Greenbelt Festival (UK) \\
& HebCelt (UK) \\
& Ilosaarirock Festival (FI) \\
& Paradise City (BE) \\
& Roskilde Festival (DK) \\
\hline Önerilenler & Gelişmekte olanlar \\
\hline $\begin{array}{l}\text { Das Fest (DE) } \\
\text { Doolin Folk Festival (IE) } \\
\text { Dubcamp Festival (FR) } \\
\text { Glastonbury Festival of Performing Arts } \\
\text { (UK) }\end{array} \quad$ Arla Food Festival (DK) \\
Hadra Trance Festival (FR) & Bayou Boogaloo (US) \\
Island Vibe Festival (AU) & Body and Soul (IE) \\
Kew The Music (UK) & Just So Festival (UK) \\
Liberation Festival Utrecht (NL) & Mandala Festival (NL) \\
Primavera Sound (ES) & Meadows Festival (UK) \\
Spring Festival Utrecht (NL) & Metaldays (SI) \\
Welcome to the Village (NL) & Mysteryland (NL) \\
& No Logo Festival (FR) \\
Nozstock: The Hidden Valley (UK) \\
Oude Muziek (NL) \\
Showmans Show (UK) \\
Uitfeest (NL) \\
\hline
\end{tabular}

We Love Green (Fransa): Paris'te düzenlenen festival, çevre sorunlarına yönelik ileri görüşlü yaklaşımı sayesinde son birkaç yılda popülerlik kazanmıştır. Festival, çevre konularıyla ilgili farkındalığı arttırmayı ve halk davranışını sanatsal ve deneysel bir şekilde etkilemeyi amaçlamaktadır. 2017 Greener Festival Ödülleri'nde çabalarından dolayı üstün başarı ödülüne layık görülmüştür. Kağıt kullanımının sınırlandırılması ve gıda atıklarının kompostlaştırılması gibi uygulamalar, We Love Green'in çevresel etkilerini azaltma yollarından bazılarıdır (Patel, 2018; www.welovegreen.fr).

Wood Festival (İngiltere): Oxfordshire'da bulunan Wood Festivali, tamamen güneş panelleri, biyodizel ve odun sobası gibi yenilenebilir enerji kaynakları ile desteklenmektedir. Aile tarafından işletilen bu festivalin bir başka özelliği de alanda portatif tuvaletlerin bulunmamasıdır. Bunun yerine kompost tuvalet olanakları sunulmaktadır. Festival, sürdürülebilir uygulamaları destekleyerek, atıklarının \%85'ini geri dönüştürmeyi başarmıştır. Çabaları için, A Greener Festival'den tam dört yıldızlı bir derecelendirme verilmiştir (Patel, 2018; www.woodfestival.com).

Tablo 1'e göre yüksek düzeyde önerilenler kategorisinde 5 farklı ülkeden 9 festival bulunmaktadır. Bu festivaller aşağıdaki gibidir: 
Cambridge Folk Festival (İngiltere): 1965'ten beri yapılan Cambridge Folk Festival, dünyanın en uzun soluklu halk festivallerinden biridir. Festival, eşsiz atmosferi ve eklektik müzik karışımıyla ünlüdür. İngiltere ve İrlanda'nın en iyi geleneksel halk sanatçıları, modern sanatçılar festivalde sahne almaktadır. Festival, 2014 yılında BBC Radyo İki İyi Gelenek Ödülü ve Karbon Ayakizi'ni azaltma konusundaki öncü tutumu nedeniyle A Greener Festival Ödülü dahil olmak üzere birçok ödül kazanmıştır. Festival kapsamında çevre dostu malzemelerin kullanımı, atık maddelerin azaltılması, gereksiz su harcamasından kaçınılması, geri dönüşümlü malzemeler kullanılması festivalin bu ödülü almasında etkili olan ekolojik uygulamalarıdır (www.cambridgelive.org.uk).

BAM18 (Brooklyn Müzik Akademisi-Hollanda): Brooklyn, New York'ta bulunan çok sanatlı bir merkezdir. 150 yıldan fazla bir süredir BAM, hem küresel hem de yerel toplulukları maceracı sanatçların, izleyicilerin ve fikirlerin evi olmuştur. Tiyatro, dans, müzik, opera, film ve daha birçok alanda dünyaca ünlü programlarla BAM, gelişmekte olan sanatçıların ve yenilikçi modern ustaların çalışmalarını sergilemektedir. 2007 yılının başlarında Next Wave Festivali ile geri dönüştürülebilen malzeme ve kağıtlar kullanılmıştır. Bunların yanı sıra BAM pazarlama faaliyetlerinin tümü elektronik posta ile yürütülmektedir. Bu sebeple genel kağıt kullanımı da azaltılmaktadır (www.bam.org).

DGTL Festival (Hollanda): Çevresel etkilerinin farkında olan bir festivaldir. Festival kapsamında malzeme döngülerini kapatmak, $\mathrm{CO}_{2}$ emisyonlarını ortadan kaldırmak ve çevre bilincini arttırmaya yardımcı olacak en yeni teknolojik gelişmeleri ve yenilikleri bulmak için çalışılmaktadır. Son birkaç yıl boyunca, DGTL ekolojik ayak izini azaltma çabalarına yoğun bir şekilde odaklanmıştır. Bu çabalar, şu anda dünya çapındaki tüm DGTL etkinliklerinde "sürdürülebilirliğin 3 büyük unsuru" olarak adlandırılan bir sürdürülebilirlik programı ile sonuçlanmıştır. Bunlar; yeniden kullanılabilir kaplar, akıllı bir enerji planı ve vejetaryen menü olarak belirlenmiştir. Festivallerin DNA'sındaki bu değişiklikler, karbon emisyonlarını büyük ölçüde düşürüyor, değerli kaynakların kurtarılmasını ve yeniden kullanılmasını ve festival alanının temiz tutulmasını sağlamaktadır (www.dgtl.nl).

Extrema Outdoor Festival (Belçika): Festival, 2017 yılının ana teması olarak küresel 1sınmayı benimsemiştir. Festival prodüksiyonu; çağdaş ve sanayileşmiş bir dünya, aşırı nüfus artışına maruz kalmış bir dünya ve dünya yörüngesini anımsatan kıyamet sonrası bir çöl şeklinde 3 ana bölüme ayrılmıştır. Bu şekilde katılımcıların bu salonları gezerken iklim değişikliğinin farkına varmaları ve bu konuda bilinç oluşturulması amaçlanmaktadır. Ayrıca 2010 yılında Love People, Love Planet projesini hayata geçirerek etkinliklerinin adım adım sürdürülebilir olmasını ve sosyal katılımlarını arttırmayı amaçlamaktadırlar (www.extremanewtork.com).

GreenBelt Festival (İngiltere): Festival kapsamında, 2017 yılında festivaldeki tüm plastik bardakları, çatal bıçak takımlarını ve yiyecek ambalajlar çıkarılmıştır. Ayrıca Yeşil Kupa uygulamasıyla $2 £$ depozito ödeyerek festival boyunca kullanılabilen bardaklar katılımcıların kullanımına sunulmuştur. Festivalde katılımcılar kullanmadıkları konserve yiyecekleri "Food Bank" uygulamasıyla bağışlayabilmektedir. Greenbelt Festival 2017 yılında A Greener Festival ödülü almıştır (www.greenbelt.org.uk).

Hebridean Celtic Festival (İngiltere): Çevre üzerindeki olumsuz etkilerini en aza indirmeyi amaçlamış bir festivaldir. Bu amaçlar; çevre mevzuatının gerekliliklerine uymak, tüm kaynak, enerji, su ve tedarik kullanımını sürdürülebilir bir şekilde yönetmek, farkındalığı arttırmak, katılımı teşvik etmek ve çalışanları çevre konularında eğitmek, tüm tedarikçilerden benzer çevre standartlarını beklemek, sanatçıların ve festival katılımcılarının festivale çevreye duyarlı bir şekilde katılmalarına yardımcı olmak, sürekli olarak performansı iyileştirmek ve kirlilik, emisyon ve atıklardan kaynaklanan etkileri azaltmak için çabalamak ve daha sürdürülebilir ulaştırma 
biçimlerini teşvik etmektir. Festival alanında plastik kuplar yerine üzerinde festivalin damgası bulunan karton kuplar kullanılmaktadır (www.hebceltfest.com).

Ilosaarirock Festival (Finlandiya): Festival, 2011, 2012, 2014 ve 2017 yıllarında A Greener Festival Ödülünü almıştır. Çevreci çalışmaları nedeniyle, Ilosaarirock Festival Finlandiya'da bu ödülü alan ilk festivaldir. Festival alanında geri dönüşüm çöp kutuları, portatif tuvaletler ve çöplerin toplanması için çöp poşetleri bulunmaktadır (www.ilosaarirock.fi).

Paradise City (Belçika): Sürdürülebilirlik konusunda bilinç aşılayan festivallerden biridir. Kamp alanlarında kampçılara geri dönüştürülebilir kamp malzemesi kiralama olanağı olması, aşırı su kullanımı ve arıtmayı mümkün olduğunca azaltması, kağıt kullanımını tamamen kesmesi, nakit paranın kullanılmadığı bir festival olması (katılımcılar telefonlarına yükleyebildikleri bir uygula ile ödeme yapabiliyorlar) sebebiyle A Greener Festival ödülü almıştır. Ayrıca Karbon Ayak İzini azaltmak için bisiklet ve toplu taşıma ile festival alanına ulaşım sağlamakta olup, yine de arabayla gelmeyi tercih edenler için arabada 2 kişiden fazla insan varsa otopark ücretini yarı yarıya indirilmesi gibi uygulamalara gidilmektedir (www.paradisecity.be).

Roskilde Festival (Danimarka): Kuzey Avrupa'daki en büyük müzik ve sanat festivalidir. Aynı zamanda, 1971 yılına kadar uzanan en eski festivallerden biridir. Roskilde Festival Charity Society, Roskilde Festival'inin organizatörüdür. Amacı, çocuklara ve gençlere fayda sağlayan girişimleri, insani ve kültürel çalışmaları desteklemektir. Çevreci tutumu sebebiyle A Greener Festival ödülünü almıştır (www.roskilde-festival.dk).

Seçkinler ve yüksek düzeyde önerilenler kategorisi dışında önerilenler ve gelişmekte olanlar kategorilerinde 10 farklı ülkeden 24 festival bulunmaktadır. A Greener Festivali kuruluşunun değerlendirdiği seçkinler ve yüksek düzeyde önerilenler kategorilerinde bulunan festivaller araştırmacılar tarafından geliştirilen kontrol listesi kullanılarak analiz edilmiştir. Bu doğrultuda enerji kaynakları, mekan düzenleme, atık yönetimi, ulaşım ve sosyal düzenlemeler alt temaları oluşturularak festivallerde bu faaliyetlerin uygulanıp uygulanmadığı değerlendirilmiştir. Tablo 2 ' de festivallerdeki eko uygulamalara ilişkin içerik analizi gösterilmektedir.

Tablo 2. Festivallerdeki Eko Uygulamalara İlişkin İçerik Analizi

\begin{tabular}{|c|c|c|c|c|c|c|c|}
\hline \multirow[b]{2}{*}{ 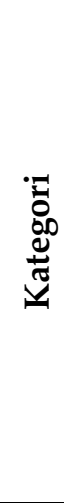 } & \multirow[b]{2}{*}{ Etkinlik } & \multicolumn{6}{|c|}{ Eko Uygulamalar } \\
\hline & & $\begin{array}{c}\text { Enerji } \\
\text { Kaynakları } \\
\text { na İlişkin } \\
\text { Düzenleme } \\
\text { ler (güneş } \\
\text { panelleri, } \\
\text { biyodizel } \\
\text { ve odun } \\
\text { sobası) }\end{array}$ & $\begin{array}{c}\text { Mekana } \\
\text { İlişkin } \\
\text { Düzenleme } \\
\text { ler }\end{array}$ & $\begin{array}{c}\text { Kullanılan } \\
\text { Malzemele } \\
\text { re İlişkin } \\
\text { Düzenleme } \\
\quad \text { ler }\end{array}$ & $\begin{array}{l}\text { Atık } \\
\text { Yöneti } \\
\text { mi }\end{array}$ & $\begin{array}{c}\text { Sosyal } \\
\text { Düzenleme } \\
\text { ler }\end{array}$ & $\begin{array}{c}\text { Ulaşı } \\
\text { m }\end{array}$ \\
\hline \multirow{2}{*}{ 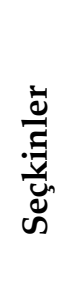 } & $\begin{array}{c}\text { Green } \\
\text { Gatherin } \\
\mathrm{g}(\mathrm{UK})\end{array}$ & $\checkmark$ & $\checkmark$ & $\checkmark$ & $\checkmark$ & $\checkmark$ & $\checkmark$ \\
\hline & $\begin{array}{c}\varnothing Y A \\
\text { Festival } \\
\text { (NO) }\end{array}$ & & $\checkmark$ & $\checkmark$ & $\checkmark$ & & $\checkmark$ \\
\hline
\end{tabular}




\begin{tabular}{|c|c|c|c|c|c|c|c|}
\hline & $\begin{array}{c}\text { We Love } \\
\text { Green } \\
\text { (FR) }\end{array}$ & $\checkmark$ & $\checkmark$ & $\checkmark$ & $\checkmark$ & $\checkmark$ & $\checkmark$ \\
\hline & $\begin{array}{c}\text { Wood } \\
\text { Festival } \\
(\mathrm{UK})\end{array}$ & $\checkmark$ & $\checkmark$ & $\checkmark$ & $\checkmark$ & & \\
\hline & $\begin{array}{c}\text { Cambrid } \\
\text { ge Folk } \\
\text { Festival } \\
\text { (UK) }\end{array}$ & & & $\checkmark$ & $\checkmark$ & $\checkmark$ & \\
\hline & $\begin{array}{c}\text { BAM18 } \\
(\mathrm{NL})\end{array}$ & & & $\checkmark$ & $\checkmark$ & $\checkmark$ & $\checkmark$ \\
\hline & $\begin{array}{l}\text { DGTL } \\
\text { festival } \\
(\mathrm{NL})\end{array}$ & $\checkmark$ & & $\checkmark$ & & $\checkmark$ & \\
\hline 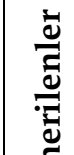 & $\begin{array}{c}\text { Extrema } \\
\text { Outdoor } \\
(\mathrm{NL})\end{array}$ & & & & & $\checkmark$ & \\
\hline 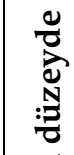 & $\begin{array}{c}\text { Greenbel } \\
\text { t Festival } \\
(\mathrm{UK})\end{array}$ & & & $\checkmark$ & $\checkmark$ & $\checkmark$ & $\checkmark$ \\
\hline : & $\begin{array}{l}\text { HebCelt } \\
\text { (UK) }\end{array}$ & & $\checkmark$ & $\checkmark$ & $\checkmark$ & $\checkmark$ & $\checkmark$ \\
\hline & $\begin{array}{c}\text { Ilosaariro } \\
\text { ck } \\
\text { Festival } \\
\text { (FI) }\end{array}$ & & $\checkmark$ & $\checkmark$ & & & \\
\hline & $\begin{array}{l}\text { Paradise } \\
\text { City (BE) }\end{array}$ & & $\checkmark$ & $\checkmark$ & $\checkmark$ & & $\checkmark$ \\
\hline & $\begin{array}{c}\text { Roskilde } \\
\text { Festival } \\
\text { (DK) }\end{array}$ & $\checkmark$ & & $\checkmark$ & $\checkmark$ & $\checkmark$ & $\checkmark$ \\
\hline
\end{tabular}

Yapılan incelemelere bakıldığında, enerji kaynaklarına ilişkin düzenlemeler konusunda seçkinler kategorisindeki dört festivalden üçünün (Green Gathering; We Love Green, Wood Festival) bu düzenlemeleri uyguladığı görülmektedir. Bu festivaller atmosferdeki sera gazı miktarını azaltmak için yenilenebilir enerji kaynaklarını (rüzgar, güneş gibi) kullanarak sürdürülebilir bir etkinliğin nasıl olması gerektiğine dair ilk büyük adımları atmışlardır. Enerji kaynaklarının etkin 
kullanımı bu kategorideki festivaller için önemli bir yer tutmaktadır. Yüksek düzeyde önerilenler kategorisindeki dokuz festivalden iki tanesinin ise (DGTL Festival, Roskilde Festival) güneş panelleri, biyodizel ve odun sobası gibi enerji kaynaklarını kullandıkları belirlenmiştir. Enerji kaynaklarının etkin kullanımı bu iki festival için önemli bir yer tutmaktadır.

Mekana ilişkin düzenlemelere bakıldığında, seçkinler kategorisindeki festivallerin tamamının festival mekanında yeşil uygulamalara (kompost tuvaletler, çöp kutuları gibi) önem verdikleri görülmektedir. Bunun aksine yüksek düzeyde önerilenler kategorisindeki üç festival (HebCelt, Ilosaarirock Festival, Paradise City) dişında mekana ilişkin çevresel düzenlemelere rastlanılmamıştır. Kompost tuvalet kullanımı sifon başına harcanan su miktarını en aza indirgemek ve tuvaletlerin temizliği için gri su kullanmak iyi bir seçenektir (Laing ve Frost, 2010). Ayrıca tüm festivallerde kullanılan çöp kutuları, çöplerin ayrıştırılarak atılması için tasarlanmıştır. Kullanılan malzemelere ilişkin düzenlemeler konusunda (yeniden kullanılabilir bardak çatal, bıçak vb.) iki kategorideki festivallerin neredeyse tamamında bir farkındalık söz konusudur. Örneğin Greenbelt festivalinde tüm plastik çatal, bıçak, bardakların kullanımı kaldırılmıştır. Katılımcıların 'Food Bank' uygulamasıyla festivalden kalan yiyecekleri bağışlaması, Greenbelt'in kullanılan malzemelere ilişkin düzenlemeler konusunda bilinçli bir festival olduğunu göstermektedir.

Festivallerdeki atık yönetimi uygulamasına bakıldığında da seçkinler kategorisinin tamamında atık yönetiminin etkili bir şekilde düzenlendiğini, yüksek düzeyde önerilenler kategorisinde ise üç festival dışında (DGTL Festival, Extrema Outdoor, Ilosaarirock Festival) atık yönetimi konusunda başarılı festivaller olduğu tespit edilmiştir. Festival yöneticilerinin, sürdürülebilir bir festivalin en önemli unsurlardan olan atık yönetimi konusunda kompostlama, yeniden kullanım, geri dönüşüm gibi uygulamaların farkında olarak bir festival organize etmeleri önem arz etmektedir (Zifkos, 2015).

Festivallerde yürütülen sosyal düzenlemeler incelendiğinde, her iki kategorideki festivallerin çoğunluğunda sosyal sorumluluk projeleri gibi faaliyetlerin farkındalık yaratmak amaciyla uygulandığı görülmektedir. Yüksek düzeyde önerilenler kategorisindeki Cambridge Folk Festival karbon ayak izini azaltmaya yönelik öncü tutumu sebebiyle AGF ödülünü almaya hak kazanmıştır. Bu da Cambridge Folk Festival'in sosyal sorumluluk projelerine önem verdiğini ve uyguladığını göstermektedir. Ayrıca Extrema Outdoor festivalleri de sürdürülebilir bir çevreye sahip olmak için çeşitli projeler yürüterek insanlarda farkındalık ve bilinç oluşmasını sağlamaktadır. Festival sosyal sorumluluk projeleri ile ön plana çıkarak AGF kuruluşu tarafından ödüllendirilmeye layık görülmüştür.

Son olarak ulaşım konusunda seçkinler kategorisindeki dört festivalden üçünün (Green Gathering, ØYA Festival, We Love Green) festival ulaşımında karbon ayak izini en aza indirgemeyi amaçladıkları belirlenmiştir. Yüksek düzeyde önerilenler kategorisinde ise beş festivalin (BAM18, Greenbelt Festival, HebCelt, Paradise City, Roskilde Festival) ulaşımın çevreye olan kötü etkilerini azaltmaya yönelik uygulamalara önem verdikleri görülmektedir. Paradise City Festivali karbon ayak izini azaltmak için bisiklet ve toplu taşıma ile festival alanına ulaşım sağlamaktadır. Eğer arabayla gelmeyi tercih edenler var ise arabada 2 kişiden fazla insan bulunduğu takdirde otopark ücretinin yarı yarıya indirilmesi gibi uygulamalar yürütülmektedir.

\section{SONUÇ}

Festivallere kültürlerin canlı bir parçası olarak birçok ülkede, şehirde ya da kasabada rastlanılmaktadır. İnsanlık tarihi boyunca festivaller, toplumların halka açık toplumsal değerlerini, kimliklerini, tarihi, statülerini ve kültürel değerlerini tanıtmak ya da kutlamak için 
belirli bir mekanda veya zamanda hizmet etmiştir (Zifkos, 2015). Ancak etkinliklerin/festivallerin gerçekleştikleri bölgeye ya da kültüre olumlu etkilerinin yanı sıra olumsuz etkileri de bulunmaktadır. Bazı etkinlikler organize edildiği bölgelerin doğal ve fiziki çevresine zarar vererek tahribata yol açmaktadır. Taşıma kapasitesinin aşımı, karbon salınımı, aşırı plastik, elektrik ve su kullanımı, ulaşım problemleri gibi unsurlar festivallerin olumsuz etkilerinden bazıları olarak görülmektedir. Dünya çapında organize edilen bazı müzik festivallerinin organizatörleri son yıllarda sürdürülebilirlik kavramını bu tür festivallerin yönetimine dahil ederek etkinliklerin potansiyel negatif etkilerini azaltmayı amaçlamaktadır. (Ensor vd., 2011). Festivallerde sürdürülebilirliğin sağlanması için, toplu taşımaya erişim, atık yönetimi ve enerji kullanımının en aza indirilmesi dahil olmak üzere çevre yanlısı uygulamalarının benimsenmesi ve yürütülmesi oldukça önemlidir (Laing ve Frost, 2010; Ahmad vd., 2013). Bundan dolay1 etkinliklerin/festivallerin daha yeşil olabilmesi için etkinlik organizatörlerinin de sürdürülebilir uygulamaların farkında olmaları gerekmektedir.

Etkinlik ve festivallerin daha sürdürülebilir ve çevre dostu olması için çalışan 'A Greener Festival' kuruluşu 2007 yılından beri eko uygulamaları benimseyen festivalleri ödüllendirmektedir (www.agreenerfestival.com). AGF kuruluşu çevre dostu festivaller ile ilgili yaptığı çalışmalarla oldukça ön planda bir kuruluş olmaya devam etmektedir. Bu çalışmada da A Greener Festival kuruluşunun 2017 yılında vermiş olduğu ödüller kapsamında seçkinler ve yüksek düzeyde önerilenler kategorilerindeki festivallerin içeriği incelenmiştir. Ödül alan festivallerin web sitelerinden elde edilen bilgilere göre hangi eko faaliyetleri uygulayıp uygulamadıkları ortaya konmuştur.

Bulguları özetlemek gerekirse, seçkinler kategorisindeki dört festivalin (Green Gathering, ØYA Festival, We Love Green, Wood Festival) enerji kaynaklarının etkin kullanımı, festival alanında kompost tuvalet ve çöp kutuları bulundurma, malzeme olarak plastikten kaçınarak karton bardak kullanımı, atık yönetiminde uzmanlık, sosyal sorumluluk projeleri ve ulaşımda karbon ayak izini en aza indirgeme gibi konularda bilinçli bir tutum sergiledikleri görülmektedir. Yüksek düzeyde önerilenler kategorisindeki dokuz festivalin ise enerji kaynaklarının etkin kullanımına ve festival mekanında uyguladıkları yeşil faaliyetlere az rastlanılmakla birlikte, plastik kullanımından kaçınma konusunda ön plana çıkmaktadırlar. Ayrıca bu kategorideki festivaller atık yönetimi ve sosyal düzenlemeler konusunda başarılı festivallerdir.

A Greener Festival ödülleri kapsamında incelenen festivallerin ilgili organizatör ve çalışanlarına bizzat ulaşılamadığından dolayı, araştırma bulguları sadece festivallerin ve A Greener Festival kuruluşunun web sitesinden elde edilmiştir. Türkiye'de yapılan çalışmalara bakıldığında 'eko etkinlik' ya da 'yeşil festival' konusunda yapılmış çalışmalar kısıtlıdır. Bu nedenle bu çalışma, gelecekteki çalışmalara kavramsal olarak katkıda bulunmayı amaçlamaktadır. Türkiyede'de düzenlenen festival ve etkinliklere bakıldığında çevreye olan olumsuz etkileri oldukça görülmektedir. Ayrıca bu çalışmayla birlikte Türkiye'de ki festival organizatörlerinde de yeşil bir etkinlik ya da festival düzenleme fikri oluşturularak, eko etkinliklerin ülkemizde de benimsenmesi ve düzenlenmesi beklenmektedir.

\section{KAYNAKÇA}

Ahmad, N. L., Rashid, W. E., Razak, N. A., Yusof, A. N., and Shah, N. S. (2013). Green Event Management and Initiatives for Sustainable Business Growth. International Journal of Trade, Economics and Finance, 4(5), 331-335. 
Aksu, M., ve İpar, M. S. (2018). Turizm İşletmelerinde Yeşil Sertifikasyon Kavramı ve Uygulamaları. L. Atay ve H. Korkmaz içinde, Turizm Isşletmelerinde Yeşil Uygulamalar (s. 23-62). Ankara: Detay Yayıncilık.

Alkan, C. (2015). Sürdürülebilir Turizm: Alaçatı Destinasyonuna Yönelik Bir Uygulama. Journal of Yasar University, 10(40), 6692-6710.

Aslan, E., ve Güneş, G. (19-21 Kasım 2015). Sürdürülebilir Turizm ve Konaklama İşletmeleri için Yeşil Anahtar Eko-Etiketi. 1. Uluslararası Türk Dünyası Turizm Sempozyumu, (s. 608-617). Kastamonu.

Atay, L., ve Dilek, S. (2013). Konaklama İşletmelerinde Yeşil Pazarlama Uygulamaları:İbis Otel Örneği. Süleyman Demirel Üniversitesi İ̈BF Dergisi, 18(1), 203-219.

Avcıkurt, C. (2015). Turizm Sosyolojsi Genel ve Yapısal Yaklaşım. Ankara: Detay Yayıncllık.

Baysal, K., Özgürel, G., ve Çeken, H. (2016). Aydın Yöresindeki Yerel Etkinliklerin Kırsal Turizm Açısından Değerlendirilmesi. Uluslararası Sosyal ve Ekonomik Bilimler Dergisi, 6(1), 100-108.

Can, E. (2015). Boş Zaman, Rekreasyon ve Etkinlik Turizmi İlişkisi. Itanbul Journal of Social Sciences(10), 1-17.

Çelik, A. (2009). Destinasyon Pazarlama Unsuru Olarak Etkinlik Turizmi ve Etkileri-İstanbul Örneği. Yüksek Lisans Tezi. Ankara.

Dickson, C., and Arcodia, C. (2010). Promoting Sustainable Event Practice: The Role of Professional Associations. International Journal of Hospitality Management, 29, 236-244.

Dickson, C., and Arcodia, C. (2010, July). Environmentally Sustainable Events: A Critical Review of the Literature. Global Events Congress IV:FestivalsEEvent Research, State of the Art, Leeds Metropolitan University, 14 .

Dodds, R., and Walsh, P. R. (2018). Assessing the Factors that Influence Waste Generation and Diversion at Canadian Festivals. Current Issues in Tourism, 1-6.

Duran, E. (2011). Turizm, Kültür ve Kimlik İlişkisi; Turizmde Toplumsal Kültürel Kimliğin Sürdürülebilirliği. Istanbul Ticaret Üniversitesi Sosyal Bilimler Dergisi, 10(19), 291-313.

Ensor, J., Robertson, M., and Ali-Knight, J. (2011). Eliciting the dynamics of leading a sustainable event: Key informant responses. Event Management, 15(4), 315-327.

Erdogan, N., ve Tosun, C. (2009). Environmental performance of tourism accommodations in the protected areas: Case of Goreme Historical National Park. International Journal of Hospitality Management, 28, 406-414.

Ertan, M. T. (2013). Etkinlik Kavramı ve Türleri. H. Ertan içinde, Etkinlik Yönetimi. Eskişehir: T.C. Anadolu Üniversitesi Yayını No: 2778.

Getz, D. (1997). Event ManagementEEvent Tourism. New York: Cognizant Communication Corporation.

Getz, D. (2009). Policy for sustainable and responsible festivals and events: institutionalization of a new paradigm. Journal of Policy Research in Tourism, Leisure and Events, 1(1), 61-78. 
Graci, S., and Dodds, R. (2008). Learn: Ecoclub Ecotourism Papers. Aralık 3, 2018 tarihinde Ecoclub: https://ecoclub.com/library/epapers/15.pdf adresinden alındı

Hauff, V. (1987). Report of the World Commission on Environment and Development: Our Common Future. Oxford University Press.

https://www.agreenerfestival.com/about-us/ [Erişim Tarihi: 28.11.2018].

https://rec.org.tr/wp-content/uploads/2016/11/iklimkyoto1.pdf [Erişim Tarihi: 10.12.2018].

https://www.cticc.co.za/sites/default/files/u123/Cape\%20Town\%20Smart_Events_Handbook.pd f [Erişim Tarihi: 29.12.2018].

http://www.greengathering.org.uk/howgreen/ [Erişim Tarihi: 01.12.2018].

http://greener-events.com/oyafestivalen/ [Erişim Tarihi: 01.12.2018].

https://www.welovegreen.fr/charte-green/ [Erişim Tarihi: 01.12.2018].

http://www.woodfestival.com/about-us/4593020878 [Erişim Tarihi: 02.12.2018].

https://www.cambridgelive.org.uk/folk-festival/folk-festival/information/environment [Erişim Tarihi: 02.12.2018].

https://www.bam.org/programs/next-wave-festival [Erişim Tarihi: 05.12.2018].

https://dgtl.nl/sustainability [Erişim Tarihi: 05.12.2018].

http://extremanetwork.com/extrema-outdoor-wint-greener-festival-award/ [Erişim Tarihi: 04.12.2018].

https://www.greenbelt.org.uk/info/a-greener-festival/ [Erişim Tarihi: 04.12.2018].

https://www.hebceltfest.com/backstage/greening/ [Erişim Tarihi: 02.12.2018].

http://www.ilosaarirock.fi/2018/english/info/environment [Erişim Tarihi: 02.12.2018].

https://paradisecity.be/green [Erişim Tarihi: 05.12.2018].

https://www.roskilde-festival.dk/en/about/sustainability/ [Erişim Tarihi:05.12.2018].

Karagöz, Y. (2017). Spss ve Amos Uygulamalı Nitel-Nicel Karma Bilimsel Araştırma Yöntemleri ve Yayın Etiği. Ankara: Nobel Akademik Yayıncilık.

Kasavana, M. L. (2008). Green Hospitality. Hospitality Upgrade: https://www.hospitalityupgrade.com/ adresinden alınmıştır

Kaypak, Ş. (2010). Ekolojik Turizmin Sürdürülebilirliği. Alanya İşletme Fakültesi Dergisi, 2(2), 93114.

Koçak, F. ve Balcı, V. (2010). Doğada Yapılan Sportif Etkinliklerde Çevresel Sürdürülebilirlik. Ankara Üniversitesi Çevrebilimleri Dergisi, 2(2), 213-222.

Kozak, M. (2015). Bilimsel Araştırma: Tasarım, Yazım ve Yayım Teknikleri. Ankara: Detay Yayıncılık.

Kuter, N. ve Ünal, H. (2009). Sürdürülebilirlik Kapsamında Ekoturizmin Çevresel, Ekonomik ve Sosyo-Kültürel Etkileri. Kastamonu Üni., Orman Fakültesi Dergisi, 9(2), 146-156. 
Laing, J., and Frost, W. (2010). How green was my festival: Exploring challenges and opportunities associated with staging green events. International Journal of Hospitality Management, $29,261-267$.

Mercan, Ş. O. ve Özkök, F. (2013). Sürdürülebilir Turizmde Yerel Yönetimlerin Önemi; Bozcaada Örneği. Sosyal ve Beşeri Bilimler Dergisi, 5(1), 409-418.

Municipality, e. (2011). Ethekwini Municipality. Aralık 2018 tarihinde Green Event Guideline: http://www.durban.gov.za/Pages/default.aspx adresinden alındı

Ndlovu, L., Boulle, J., Diederichs-Mander, N., Hawes, J., Walker, P., and Stead, G. (2011). eThekwini Municipality. Green Event Guideline: http://www.durban.gov.za/Pages/default.aspx adresinden alınmıştır

Patel, A. (2018). Business Destinations. The 10 best environmentally friendly festivals: www.businessdestinations.com adresinden alınmıştır

Presbury, R., and Edwards, D. (2005). Incorporatıng Sustainability In Meetıngs And Event Management Education. International Journal Of Event Management Research, 1(1), 30-45.

Thøgersen, J., Haugaard, P., and Olesen, A. (2010). Consumer Responses to Ecolabels. European Journal of Marketing, 44(11/12), 1787-1810.

Tosun, C. (2001). Challenges of sustainable tourism development in the developing world: the case of Turkey. Tourism management, 22(3), 289-303.

Tosun, C. (2009). Promoting a Sustainable Tourism: National Study for Turkey. UNEP/MAP/BLUE PLAN: Promoting Sustainable Tourism in the Mediterranean: Proceedings of the Regional Workshop.

Tutar, F. K. (2015). Yeşil Ekonomi, Yeşil Turizm: Türkiye'de Turizm Sektöründe Yeni Trend Yeşillenen Oteller Projesi. Akademik Sosyal Araştırmalar Dergisi, 3(13), 328-352.

Uçak, S., ve Villi, B. (2013). Eko-Etkinlik Kapsamında Çevresel Etki Göstergeleri:Oecd Değerlendirmesi. Sosyal ve Beşeri Bilimler Dergisi, 5(1), 397-408.

Uygur, S. M., ve Çelik, A. (2010). Etkinlik Turizminin Algılanan Sosyo-Ekonomik Etkilerini Belirlemeye Yönelik İstanbul Destinasyonunda Bir Araştırma. İşletme Fakültesi Dergisi, 11(1), 3550.

Vatan, A., ve Poyraz, M. (2016). Nasıl Sürdürülebilir Otel Olunur? Çatalhöyük Uluslararası Turizm ve Sosyal Araştırmalar Dergisi(1), 15-30.

Wong, I. A., Wan, Y. K., and Qi, S. (2015). Green events, value perceptions, and the role of consumer involvement in festival design and performance. Journal of Sustainable Tourism, 23(2), 294-315.

Yolal, M. (2017). Türkiye'nin Etkinlik Turizmi Potansiyelinin Değerlendirilmesi. Çatalhöyük Uluslararası Turizm ve Sosyal Araştırmalar Dergisi(2), 35-51.

Zifkos, G. (2015). Sustainability Everywhere: Problematising the "Sustainable Festival" Phenomenon. Tourism Planning and Development, 12(1), 6-19. 
Zitz, N. (2014). Awareness and Perception of Green Meetings and Events among Austrian Companies. Modul Vienna University; Lisans Tezi. 